\title{
Inauguración del Centro de Estudios de Política Comercial
}

Palabras promunciadas por el profesor Francisco Prieto

en la inauguración del Centro de Estudios de Política Comercial del Instituto de Estudios Internacionales de la Universidad de Chile.

Deseo partir agradeciendo a todos quienes nos acompañan en esta ceremonia y señalar que es para mí un honor poder dirigirles unas palabras con ocasión de la inauguración del Centro de Estudios de Política Comercial de nuestro Instituto. También quiero agradecer a nuestra directora, señora Jeannette Irigoin y, a través suyo, al Consejo Académico el que, confirmando su vocación interdisciplinaria, autorizó la creación de este nuevo centro de estudios. Las fortalezas del Instituto en materias internacionales ligadas a los asuntos jurídicos, políticos y económicos son una base de sustento invalorable para nuestros trabajos.

En muchos encuentros con colegas extranjeros interesados en estos temas casi siempre terminamos preguntándonos lo mismo: la política comercial: ¿ángel o demonio de nuestras sociedades?

Más aún, a estos encuentros nos invitan justamente para procurar arrojar luces sobre un sinfin de incertidumbres relacionadas con las repercusiones políticas, sociales y económicas de la política comercial. Esto nos obliga a saber más res- 
pecto de la incidencia de la política comercial en el crecimiento, en el desarrollo, en la transformación productiva, en la soberanía nacional, en la lucha contra la pobreza y contra la corrupción, en el bienestar social, en la calidad del medio ambiente y del empleo, en las cuestiones de género y en la defensa de nuestro acervo cultural, etc.

Muy probablemente estas preguntas surgen del hecho de que la política comercial se ha convertido en uno de los mecanismos privilegiados para adelantar la transformación económica, institucional y normativa necesaria para el desarrollo de los países.

Hasta hace poco la política comercial solía ocuparse primordialmente de cuestiones tales como aranceles, tipo de cambio, restricciones cuantitativas y análisis de los efectos en los precios relativos de los bienes que esas modificaciones ocasionan. También, y ayudados por la econometría, se proyectaban sus efectos en la producción, el consumo y el comercio y se aventuraban juicios sobre los impactos en el empleo, los equilibrios macro y la recaudación fiscal.

Sin embargo, y como resultado de la profundización de la integración económica mundial, hoy encontramos un escenario en el cual la política comercial ha ido incorporando a su esfera de operaciones un instrumental mucho más amplio. Ello exige tomar decisiones sobre un amplio espectro de materias, que va mucho más allá de ese limitado conjunto de instrumentos y en el cual el énfasis en los fundamentos institucionales y normativos es determinante.

Esta continua ampliación del espectro de materias que conforman la política comercial contemporánea resulta en parte de la creciente transnacionalización de las actividades productivas. Este fenómeno, apoyado por la mayor interconectividad que permiten las tecnologías de la información, va exigiendo nuevas y más creativas formas de aprovechar esa interdependencia económica de los países en beneficio de nuestros propios pueblos. Por consiguiente, la vieja institucionalidad económica internacional basada en concepciones del Estado-nación que se generó en el siglo XIX ha probado ser insuficiente para las realidades de la actual economía global. En consecuencia, las nuevas formas de organización y gestión del sistema productivo mundial han propiciado un creciente reacomodo de las instituciones y de las normativas nacionales y supranacionales que regulan las relaciones económicas y comer- 
ciales entre los países. La propia creación de la Organización Mundial de Comercio en 1995 y la ampliación de las disciplinas a las cuales le han otorgado competencias los Gobiernos es quizás la más elocuente demostración de este fenómeno.

Hoy las decisiones que deben adoptar los Gobiernos en estas materias se refieren a temas tan heterogéneos como el comercio de servicios, las inversiones extranjeras, el tamaño y responsabilidad del Estado, su rol como proveedor de bienes y servicios y como impulsor de nuevas instituciones y normas que propicien una mayor eficiencia de la actividad económica. Todo ello sin olvidar la necesidad de definir modalidades más eficaces para alcanzar la variada gama de objetivos sociales que persigue el conjunto de políticas públicas al menor costo y con las menores distorsiones posible. También forman parte de la política comercial los temas relativos a la movilidad internacional de personas y la participación en mercados laborales extra-nacionales; la normativa y protección de la propiedad intelectual y su incidencia en el desarrollo de nuevas ideas y conocimientos; las definiciones en materia de normas laborales y ambientales que afectarán a esta y a las futuras generaciones y de su relación, no siempre virtuosa, con el comercio internacional.

Estos cambios han dado origen a la aparición de nuevos actores deseosos de hacer ver sus puntos de vista y de defender sus respectivos intereses y preocupaciones. Así se han ido generando reformulaciones importantes en los patrones de conducta al interior del Estado, en las relaciones del Estado con la sociedad civil, incluidos empresarios, trabajadores y organizaciones no gubernamentales, y en las de ambos con el resto del mundo.

Igualmente, la gestación y puesta en marcha de la política comercial contemporánea debe abordarse de manera interdisciplinaria como puede hacerse al amparo del Instituto de Estudios Internacionales de nuestra Universidad.

En los últimos años, nuestro país ha vivido un creciente proceso de integración a la economía mundial. Hemos participado activamente en las negociaciones multilaterales que se llevan a cabo en la Organización Mundial de Comercio, en los diferentes foros regionales de los cuales formamos parte y hemos suscrito un gran número de acuerdos preferenciales bilaterales. Esta es una razón más tras la creación del Centro de Estudios de Política Comercial 
en nuestro Instituto y de su aspiración a convertirse en eficiente punto de encuentro para representantes del Gobierno, el mundo académico, el sector privado y la sociedad civil. Esperamos con ello contribuir positivamente a facilitar el desarrollo de mejores y más eficaces canales para el desarrollo de las políticas públicas relacionadas con estos temas.

Surge entonces como respuesta a la necesidad de fortalecer el análisis y la reflexión interdisciplinarios la creación de un Centro de Estudios de Política Comercial en el seno del Instituto de Estudios Internacionales de la Universidad de Chile. Consecuentemente, el Centro se ha propuesto como objetivos los de promover, coordinar y ejecutar proyectos de investigación, capacitación y docencia relacionados con esta materia y con sus nuevos campos de análisis.

En ese contexto, nuestro Centro privilegiará como material de estudio el examen comparativo de las experiencias nacionales en materia de política comercial, con énfasis en la vinculación entre estas y el desarrollo institucional y normativo de los países en que se desarrollan y ejecutan tales políticas. En esto no podemos desconocer las nuevas visiones que surgen en países de nuestra región y que plantean nuevas formas de encarar las relaciones económicas internacionales. Es necesario estudiarlas y procurar comprender sus verdaderos alcances con el objeto de identificar afinidades y coincidencias que puedan potenciar acciones comunes para la defensa de nuestros intereses en el contexto global. Por ello nos empeñaremos en formar redes de cooperación con centros de estudio de los países de América Latina y otras fuentes de cooperación. Deseo destacar aquí nuestra provechosa cooperación con la OMC. Este año se llevará a cabo la segunda versión del Curso Regional de Política Comercial de la OMC. Este curso tiene por objeto formar negociadores comerciales para los gobiernos de América Latina y el Caribe de habla hispana y permite desarrollar una vasta red de funcionarios gubernamentales, académicos de la región y miembros de la Secretaría de la OMC.

Creemos que esta tarea puede ayudar a generar una activa y útil retroalimentación entre todos los actores sociales involucrados, con la consiguiente mejora de la calidad de las políticas públicas relacionadas con la inserción de Chile y otros países en desarrollo en la economía global. 
Al concluir, quiero aprovechar la oportunidad para agradecer

Documentos a todas las personalidades -tanto de Gobierno como del sector privado y académico- que tan generosa y desinteresadamente han aceptado integrar nuestro Comité Ejecutivo. Sus aportes serán una guía insustituible para mantener la relevancia de los trabajos de nuestro Centro. Y en este mismo sentido, quiero rendir especial homenaje a nuestro principal orador de esta ceremonia y miembro del Comité Ejecutivo, el señor director general adjunto de la OMC, don Alejandro Jara Puga. Su presencia aquí nos llena de orgullo y reconocimiento. Su destacada carrera en la diplomacia comercial de Chile, los importantes logros que tan exitosamente impulsó desde sus responsabilidades en nuestra Cancillería, su talento y firme decisión de contribuir a la formación de las jóvenes generaciones de negociadores comerciales chilenos y su merecida designación en el alto cargo internacional que hoy ocupa definen elocuentemente lo que son las cualidades de un servidor público de excelencia. Estas cualidades deben servir de ejemplo para todos aquellos que se interesan por los asuntos públicos internacionales. Me honro especialmente de contarme entre sus amigos y de haber tenido el privilegio de trabajar por varios años bajo su brillante dirección en nuestra Cancillería. Y, por supuesto, gracias Alejandro por tu apoyo entusiasta a nuestro recién creado Centro. Muchas gracias a todos por vuestra presencia en este acto. 